\title{
The solute carrier SLC7A8 is a marker of favourable prognosis in ER-positive low proliferative invasive breast cancer
}

\author{
Rokaya El Ansari ${ }^{1,3} \cdot$ Lutfi Alfarsi $^{1} \cdot$ Madeleine L. Craze ${ }^{1} \cdot$ Brendah K. Masisi $^{1} \cdot \operatorname{lan}$ O. Ellis ${ }^{1,2} \cdot$ Emad A. Rakha $^{1,2}$. \\ Andrew R. Green ${ }^{1}$
}

Received: 24 October 2019 / Accepted: 29 February 2020 / Published online: 21 March 2020

(c) The Author(s) 2020

\begin{abstract}
Purpose Breast cancer (BC) is a heterogeneous disease consisting of various subtypes, with different prognostic and therapeutic outcomes. The amino acid transporter, SLC7A8, is overexpressed in oestrogen receptor-positive BC. However, the consequence of this overexpression, in terms of disease prognosis, is still obscure. This study aimed to evaluate the biological and prognostic value of SLC7A8 in BC with emphasis on the intrinsic molecular subtypes.

Methods SLC7A8 was assessed at the genomic, using METABRIC data $(n=1980)$, and proteomic, using immunohistochemistry and TMA $(n=1562)$, levels in well-characterised primary BC cohorts. SLC7A8 expression was examined with clinicopathological parameters, molecular subtypes, and patient outcome.

Results SLC7A8 mRNA and SLC7A8 protein expression were strongly associated with good prognostic features, including small tumour size, low tumour grade, and good Nottingham Prognostic Index (NPI) (all $P<0.05$ ). Expression of $S L C 7 A 8$ mRNA was higher in luminal tumours compared to other subtypes $(P<0.001)$. High expression of SLC7A8 mRNA and SLC7A8 protein was associated with good patient outcome $(P \leq 0.001)$ but only in the low proliferative ER+/luminal A tumours $(P=0.01)$. In multivariate analysis, SLC7A8 mRNA and SLC7A8 protein were independent factors for longer breast cancer specific survival $(P=0.01$ and $P=0.03)$, respectively.

Conclusion SLC7A8 appears to play a role in BC and is a marker for favourable prognosis in the most predominant, ER+ low proliferative/luminal A, BC subtype. Functional assessment is necessary to reveal the specific role played by SLC7A8 in $\mathrm{ER}+\mathrm{BC}$.
\end{abstract}

Keywords SLC7A8 $\cdot$ Breast cancer $\cdot$ Prognosis

Electronic supplementary material The online version of this article (https://doi.org/10.1007/s10549-020-05586-6) contains supplementary material, which is available to authorised users.

Andrew R. Green

andrew.green@nottingham.ac.uk

1 Nottingham Breast Cancer Research Centre, Division of Cancer and Stem Cells, School of Medicine, University of Nottingham Biodiscovery Institute, University Park, Nottingham NG7 2RD, UK

2 Histopathology, Nottingham University Hospitals NHS Trust, Hucknall Road, Nottingham NG5 1PB, UK

3 Department of Pathology, Faculty of Medicine, University of Tripoli, Tripoli, Libya

\section{Introduction}

Many cancer cells alter their metabolism to provide energy and cellular building blocks required for their rapid proliferation. Amino acids, particularly glutamine and leucine, are essential for cancer cell growth, as they are critical for controlling protein translation and driving cell cycle progression through regulation of the mammalian target of rapamycin complex1 (mTORC1) pathway [1, 2]. This pivotal need for intracellular amino acids is reflected in the increased expression of amino acid transport systems in the majority of cancers, which is regulated by various transcription factors such as c-MYC, hormone receptors, and nutrient starvation responses [3-5].

Solute Carrier Family 7 Member 8 (SLC7A8) and Member 5 (SLC7A5) are sodium-independent amino acid exchangers (antiports), which transport small and large 
neutral amino acids, such as alanine, serine, threonine, cysteine, phenylalanine, tyrosine, leucine, and glutamine [6]. Both solute carriers require heterodimerisation with the heavy chain of SLC3A2 for their proper localisation in the plasma membrane [7-9].

Although the function of SLC7A8 and SLC7A5 are similar, the former displays relatively lower affinity for its substrates, glutamine, and serine. SLC7A5 has been extensively studied in a variety of cancers and it is regulated by the oncogene c-MYC [10-13]. We have previously described the potential utility of SLC7A5 as a poor prognostic factor for the highly proliferative breast cancer (BC) subtypes [14]. However, there is limited information whether SLC7A8 plays an equal role in BC. Previous studies showed that SLC7A8 is upregulated in ER+BC and it is controlled by oestrogen $[4,15]$. Luo et al. also identified SLC7A8 as a novel progesterone target gene in uterine leiomyoma cells [16]. To our knowledge, the prognostic impact of SLC7A8 has not been studied.

In this study, we aimed to assess $S L C 7 A 8$ gene copy number $(\mathrm{CN})$ and mRNA expression, alongside SLC7A8 protein expression in large and well-characterised cohorts of $\mathrm{BC}$ to determine its clinicopathological and prognostic value with emphasis on the different molecular classes.

\section{Material and methods}

\section{SLC7A8 genomic profiling}

SLC7A8 gene copy number and gene expression were evaluated using the Molecular Taxonomy of Breast Cancer International Consortium (METABRIC) cohort of invasive $\mathrm{BC}(n=1980)$ [17]. In this study, DNA/RNA was isolated from fresh frozen samples and transcriptional profiling was acquired using the Illumina HT-12v3 platforms. Data were pre-processed and normalised as described previously [17]. Patients involved in the study who were Oestrogen Receptor-negative (ER-) and Lymph Node (LN)-positive received adjuvant chemotherapy, while ER+ and/or LN- patients did not receive adjuvant chemotherapy. Dichotomisation of SLC7A8 mRNA was achieved using X-tile (version 3.6.1, Yale University, USA), based on prediction of Breast Cancer Specific Survival (BCSS). SLC7A8 mRNA expression was associated with clinicopathological parameters, molecular subtypes and patient outcome.

The online dataset, Breast Cancer Gene-Expression Miner v4.0 (https://bcgenex.centregauducheau.fr), was used for external validation of $S L C 7 A 8$ mRNA expression.

\section{SLC7A8 protein expression}

Immunhistochemistry for SLC7A8 was performed using a well-characterised cohort of early stage primary operable invasive BC patients aged $\leq 70$ years. Patients presented at Nottingham City Hospital between 1989 and 2006. Patients were managed based on a uniform protocol. Clinical history, tumour characteristics, information on therapy, and outcomes are prospectively maintained. Outcome data included development and time to distant metastasis (DM) and BCSS.

Supplementary Table 1 summarises the clinicopathological parameters for the Nottingham and METABRIC series.

\section{Western blotting}

The specificity of anti-SLC7A8 primary antibody (HPA051950, Sigma-Aldrich, UK) was validated using Western blotting in BC lysates (American Type Culture Collection; Rockville, MD, USA) as previously described [18]. A single band for SLC7A8 was visualised at the correct predicted size ( $58 \mathrm{KDa})$ (Supplementary Fig. 1).

\section{Tissue arrays and Immunohistochemistry (IHC)}

Tumour samples, $0.6 \mathrm{~mm}$ cores, were arrayed as previously described $[14,19]$. Immunohistochemical staining was performed on $4 \mu \mathrm{m}$ TMA sections using Novolink polymer detection system (Leica Biosystems, RE7150-K) as per the manufacturer's instructions.

Stained TMA sections were scanned using high resolution digital images (NanoZoomer; Hamamatsu Photonics, Welwyn Garden City, UK), at $\times 20$ magnification. Modified histochemical score (H-score) was applied to evaluate SLC7A8 immunostaining. This includes a semi-quantitative assessment of both the percentage and the intensity of stained cells [20]. Staining intensity was graded as: 0 , negative; 1 , weak; 2 , medium; 3 , strong and the percentage of the positively stained tumour cells was estimated subjectively. The final $\mathrm{H}$-score was calculated multiplying the intensity $(0-3)$ by the percentage of positive cells $(0-100)$, producing a total range of 0-300. Dichotomisation of SLC7A8 protein expression was determined using X-tile software in predicting BCSS.

Immunhistochemical staining and dichotomisation of the other biomarkers included in this study were as per previous publications [14, 18-22]. ER and PgR positivity was defined as $\geq 1 \%$ staining. Immunoreactivity of HER 2 was scored using standard HercepTest guidelines (Dako). Chromogenic in situ Hybridisation (CISH) was used to quantify HER2 gene amplification in borderline cases using the HER2 FISH pharmDx ${ }^{\mathrm{TM}}$ plus HER2 CISH pharmDx ${ }^{\mathrm{TM}}$ kit (Dako) and 
was assessed according to the American Society of Clinical Oncology guidelines. BC molecular subtypes were defined, based on tumour IHC profile and the Elston-Ellis [23] mitotic score as: ER+/HER2- Low Proliferation (mitotic score 1), ER+/HER2- high Proliferation (mitotic score 2 and 3), HER2 - positive class: HER2+ regardless of ER status, Triple Negative (TN): ER-, PgR-, and HER2- [24].

\section{Statistical analysis}

SPSS 24.0 statistical software (SPSS Inc., Chicago, IL, USA) was applied for statistical analysis. The Chi-square test was carried out for inter-relationships between categorical variables. One-way ANOVA with post hoc Tukey multiple comparison test and Pearson's correlation coefficient was performed to analyse the association between continuous variables. Survival curves were examined by Kaplan-Meier with Log Rank test. Cox's proportional hazard method was performed for multivariate analysis to identify the independent prognostic/predictive factors. $P$ values were adjusted using Bonferroni correction for multiple testing, whenever applicable. A $P$ value $<0.05$ was considered significant. The study endpoints were 10-year BCSS or distant metastasis free survival (DMFS). This study complied with reporting recommendations for tumour marker prognostic studies (REMARK) criteria [25].
This study was approved by the Nottingham Research Ethics Committee 2 under the title 'Development of a molecular genetic classification of breast cancer' and the North West-Greater Manchester Central Research Ethics Committee under the title 'Nottingham Health Science Biobank (NHSB)' reference number 15/NW/0685.

\section{Results}

\section{SLC7A8 in breast cancer}

High SLC7A8 mRNA expression was observed in almost two-third (67\%) of the METABRIC BC cases. A total of 90/1,980 (4.5\%) of cases showed SLC7A8 copy number (CN) gain, whereas 45/1,980 (2.3\%) cases showed a CN loss. A significant association was observed between SLC7A8 copy number variation (CNV) and SLC7A 8 mRNA expression $(P<0.0001$, Fig. 1a). There was a positive association between SLC7A8 CN gain and CN gain of the tumour suppressor gene, TP53 $(P<0.0001$, Supplementary Table 2$)$.

SLC7A8 protein expression was observed, predominantly in the cytoplasm of invasive $\mathrm{BC}$ cells, with expression levels varying from absent to high (Fig. $2 \mathrm{a}$ and $\mathrm{b}$ ). Positive SLC7A8 protein expression ( $>20 \mathrm{H}$-score) was observed in $177 / 1560(11 \%)$ of cases.
A

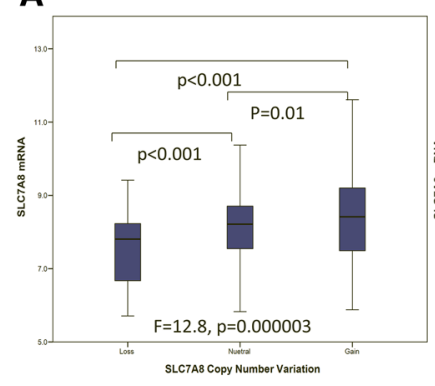

E

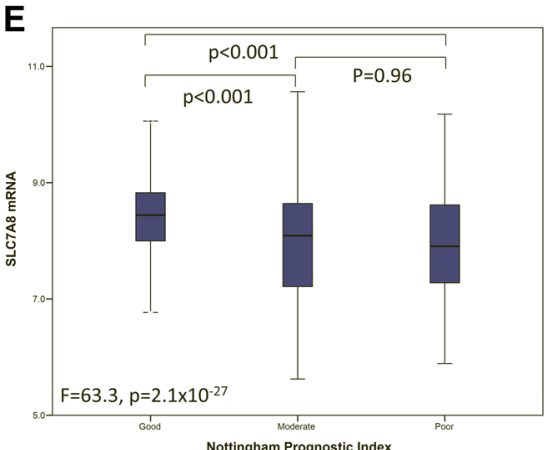

B C

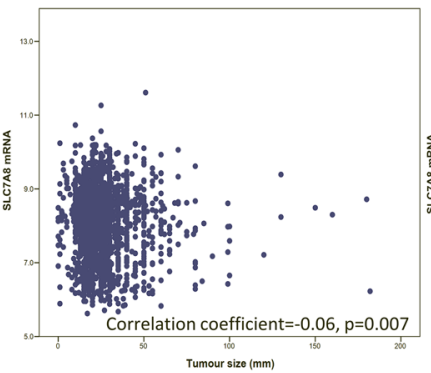

C

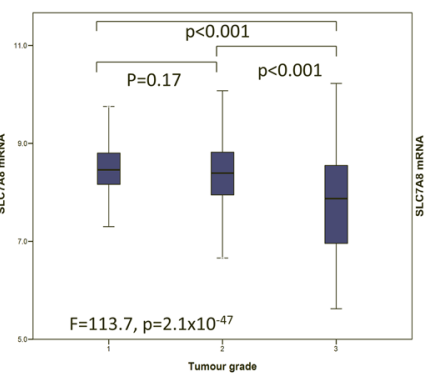

D

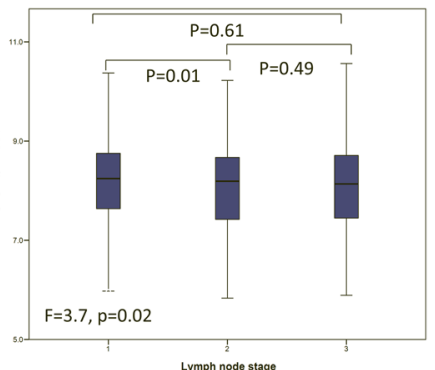

$\mathbf{F}$

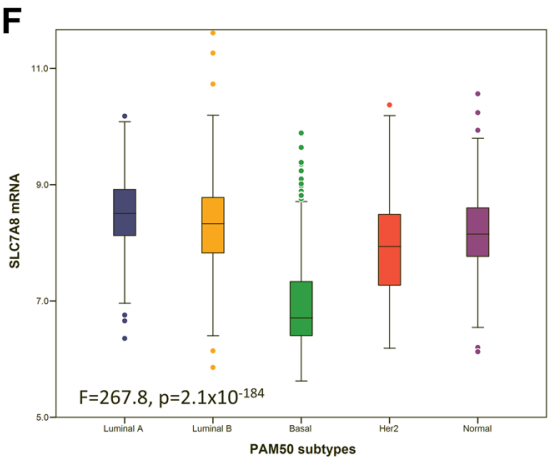

G

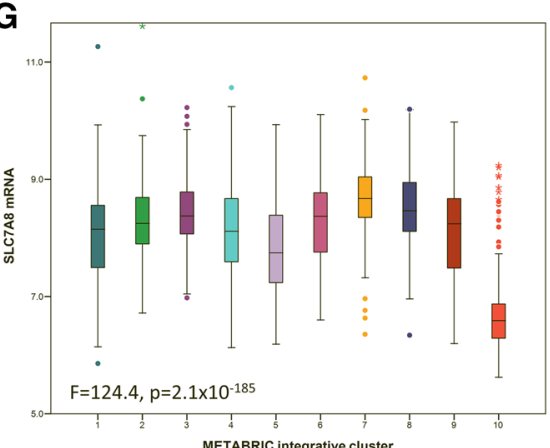

Fig. 1 SLC7A8 mRNA expression and its association with copy number aberrations, clinicopathological parameters and molecular subtypes: a SLC7A8 and copy number aberrations, b SLC7A8 and tumour size, c $S L C 7 A 8$ and tumour grade, d SLC7A 8 and lymph node stage, e $S L C 7 A 8$ and NPI, f $S L C 7 A 8$ and PAM50 subtypes, g $S L C 7 A 8$ and METABRIC Integrative Clusters. Pearson correlation was used for two variables and One-way ANOVA with post hoc tukey test for more than two variables 
Fig. 2 SLC7A8 protein expression in invasive breast cancer cores. a Positive IHC expression, b negative IHC expression

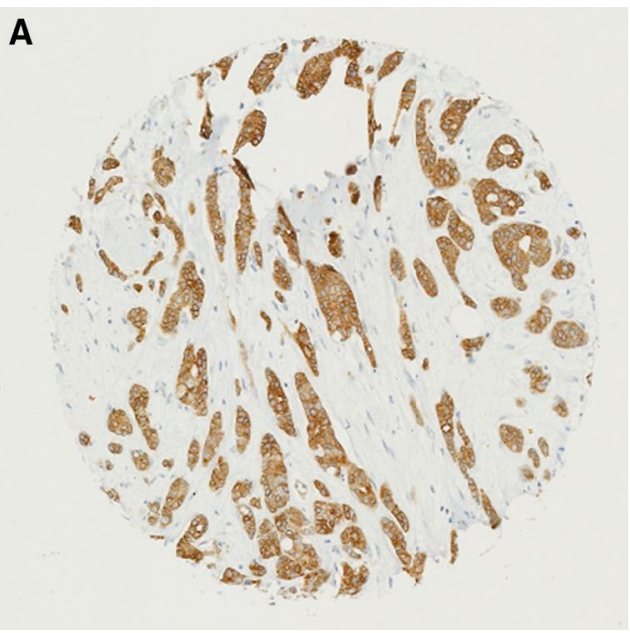

B

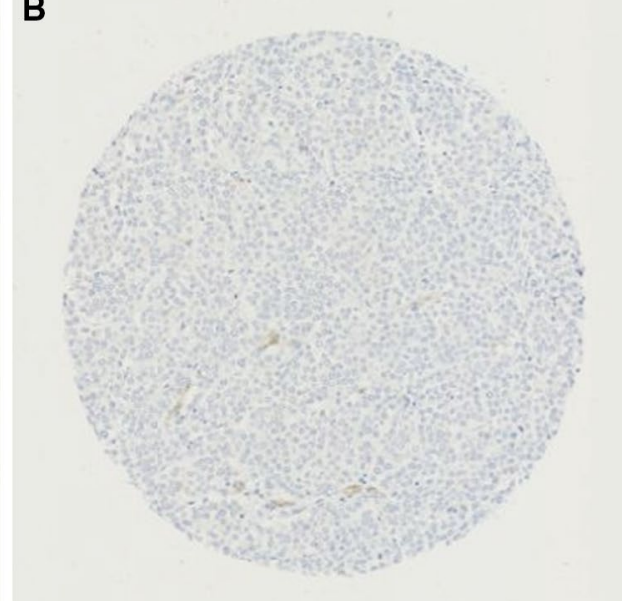

\section{SLC7A8 and clinicopathological parameters}

High SLC7A8 mRNA expression was significantly associated with good prognostic parameters, including smaller tumour size (Fig. 1b, $P=0.007$ ), lower tumour grade (Fig. 1c, $P<0.001$ ), and good Nottingham Prognostic Index (NPI) (Fig. 1e, $P<0.001$ ). These associations were confirmed using the Breast Cancer Gene-Expression Miner (Supplementary Fig. 2A-2C).

Similar associations were observed with SLC7A8 protein expression. Table 1 summarises the observed findings between high SLC7A8 protein and good prognostic factors, including small tumour size $(P=0.03)$, low tumour grade $(P<0.001)$, and good NPI $(P<0.001)$.

\section{SLC7A8 expression in molecular BC subtypes}

High expression of SLC7A8 mRNA was significantly associated with hormone receptor positive (ER+ and $\mathrm{PgR}+)$ and HER2- BC (all $P<0.001$, Table 2). Likewise, SLC7A8 mRNA was highly expressed in non-triple negative (TN) compared with TN tumours $(P<0.001$, Table 2$)$. These results were validated using Breast Cancer Gene-Expression Miner (Supplementary Fig 2D-2G). Similarly, high SLC7A8 protein expression was associated with HER2 negative $\mathrm{BC}(P=0.01)$ and although it was expressed primarily in hormone receptor positive tumours this did not reach significance (Table 2).

Regarding the association of $S L C 7 A 8 \mathrm{CN}$ and mRNA with the intrinsic (PAM50) subtypes, $S L C 7 A 8 \mathrm{CN}$ gain was mainly observed in luminal B tumours $(P<0.001$, Supplementary Table 2), whereas high mRNA expression was observed primarily in luminal A and B tumours and to lesser extent in HER2+BC $(P<0.001$, Fig. 1f $)$. In the METABRIC Integrative Clusters, high SLC7A8 mRNA expression was associated with clusters 7 and 8 which embrace ER+ tumours predominately of the luminal A intrinsic subtype
$(P<0.001$, Fig. $1 \mathrm{~g})$. Similar associations of $S L C 7 A 8$ mRNA with the molecular subtypes were seen using Breast Cancer Gene-Expression Miner (Supplementary Fig. 2H).

Although the result of the association of SLC7A8 protein in the defined IHC subtypes were not nominally significant, it also showed higher SLC7A8 expression in the ER+ low proliferation tumours compared with the other subtypes (Table 1).

\section{SLC7 A8 expression and other associated markers}

The correlations of SLC7A8 mRNA with other relevant genes were investigated using the METABRIC dataset (Table 3). These genes were selected based on previous publications showing a functional association between SLC7A8 and glutamine transport or metabolism [6, 26-28]. High SLC7A8 mRNA expression was significantly associated with enzymes involved in glutamine metabolism: glutaminase ( $G L S$ and $G L S 2 ; P<0.001$ ), which mediate the conversion of glutamine to glutamate. While the correlation with $G L S$ was negative, it was positive with $G L S 2$. There was also a positive association with the enzymes which mediate conversion of glutamine to proline, namely, ALDH4AI and $P R O D H(P<0.001)$. In contrast, some glutamine transporters were negatively correlated with $S L C 7 A 8$ expression $(P \leq 0.009)$, including SLC1A5, SLC7A5, SLC7A6, SLC7A7, and SLC38A3, while others showed a positive association, including SLC7A9, SLC38A1, SLC38A2, and SLC38A7 $(P \leq 0.003)$. The associations between SLC7A8 and glutamine metabolic enzymes and transporters were primarily observed within luminal A tumours and to lesser extent in luminal B, HER2+ and TN subtypes. High SLC7A8 mRNA expression was associated with tumours which showed wild-type TP53 expression $(P<0.001$, Table 3$)$. 
Table 1 Clinicopathological associations of the SLC7A8 protein expression in breast cancer

\begin{tabular}{|c|c|c|c|c|}
\hline \multirow[t]{2}{*}{ Parameter } & \multicolumn{2}{|c|}{ SLC7A8 protein } & \multirow[t]{2}{*}{$\chi^{2}(P$ value $)$} & \multirow[t]{2}{*}{ Adjusted $P$ value } \\
\hline & $\begin{array}{l}\text { Low } \\
n(\%)\end{array}$ & $\begin{array}{l}\text { High } \\
n(\%)\end{array}$ & & \\
\hline \multicolumn{5}{|l|}{ Tumour size } \\
\hline$<2 \mathrm{~cm}$ & $756(87.1)$ & $112(12.9)$ & $7.03(0.008)$ & $\mathbf{0 . 0 3}$ \\
\hline$\geq 2 \mathrm{~cm}$ & $623(91.3)$ & $59(8.7)$ & & \\
\hline \multicolumn{5}{|l|}{ Tumour grade } \\
\hline 1 & $182(82.7)$ & $38(17.3)$ & $20.62(0.00003)$ & 0.0002 \\
\hline 2 & $491(86.7)$ & $75(13.3)$ & & \\
\hline 3 & $704(92.4)$ & $58(7.6)$ & & \\
\hline \multicolumn{5}{|l|}{ Lymph node stage } \\
\hline 1 & $840(87.9)$ & $116(12.1)$ & $4.84(0.08)$ & 0.16 \\
\hline 2 & $400(89.7)$ & $46(10.3)$ & & \\
\hline 3 & $136(93.8)$ & $9(6.2)$ & & \\
\hline \multicolumn{5}{|l|}{ Nottingham Prognostic Index } \\
\hline Good & $397(83.8)$ & $77(16.2)$ & $20.09(0.00004)$ & 0.0002 \\
\hline Moderate & $746(90.6)$ & $77(9.4)$ & & \\
\hline Poor & $234(93.2)$ & $17(6.8)$ & & \\
\hline \multicolumn{5}{|l|}{ IHC subtypes } \\
\hline ER+/HER2- low proliferation & $706(87.7)$ & $99(12.3)$ & & \\
\hline ER+/HER2- high proliferation & $230(90.9)$ & $23(9.1)$ & 5.67 & \\
\hline Triple negative & $207(88.5)$ & $27(11.5)$ & $(0.128)$ & 0.24 \\
\hline HER2+ & $145(93.5)$ & $10(6.5)$ & & \\
\hline \multicolumn{5}{|l|}{ Histological type } \\
\hline Ductal (including mixed) & 1217 (89.6) & $142(10.4)$ & & \\
\hline Lobular & $88(87.1)$ & $13(12.9)$ & 15.93 & \\
\hline Medullary & $23(92.0)$ & $2(8.0)$ & $(0.01)$ & 0.03 \\
\hline Miscellaneous & $7(77.8)$ & $2(22.2)$ & & \\
\hline Special type & $41(78.8)$ & $11(21.2)$ & & \\
\hline
\end{tabular}

Bold indicates the significant values
SLC7A8 protein was significantly expressed with high GLS and GLS2 enzymes $(P<0.001$ and $P=0.006$, Table 4$)$, respectively. High PRODH, ALDH18A1, and ALDH4A1 were expressed in breast tumours with high SLC7A8 expression (all $P \leq 0.004$, Table 4). High SLC7A8 expression was associated with low levels of SLC7A5 $(P<0.03$, Table 4$)$, whereas paradoxical associations were observed with the other transporters, SLC38A2 and SLC7A11 $(P \leq 0.02$, Table 4).

\section{SLC7A8 expression and patient outcome}

High expression of SLC7A8 mRNA and protein was associated with longer BCSS $(P \leq 0.001$, Figs. $3 a$ and $4 a)$. While $S L C 7 A 8$ mRNA expression was not predictive for BCSS in any specific molecular class (Fig. 3b-e), high expression of SLC7A8 protein was predictive of good survival in only the $\mathrm{ER}+$ low proliferation tumours $(P=0.01$, Fig. $4 \mathrm{~b})$. There was no association between SLC7A8 protein and outcome in ER+ high proliferation, HER2+ or TN subtypes (Fig. 4c-e).
Multivariate Cox regression analysis showed that $S L C 7 A 8$ mRNA and SLC7A8 protein were predictors of longer BCSS independent of tumour size, grade, and lymph node stage ( $P=0.01$ and $P=0.03$, Table 5 ) respectively.

Likewise, high SLC7A8 protein expression was associated with longer distant metastases-free survival (DMFS) $(P<0.001$, Supplementary Fig. 3A) within the ER+ low proliferation class $(P=0.003$, Supplementary Fig. $3 \mathrm{~B})$ but not with other subtypes (Supplementary Fig. 3C, 2E). The relationship between high $S L C 7 A 8$ mRNA expression and good patient outcome was verified using Breast Cancer Gene-Expression Miner (Supplementary Fig. 4A, 4B).

\section{Discussion}

$\mathrm{BC}$ represents a group of heterogeneous diseases that vary at the histopathological and molecular levels. These subtypes differ in their biology, clinical outcome, and response to therapy [29]. In addition, different BC subtypes showed 
Table 2 Expression of SLC7A8 in breast cancer and the expression of other molecular biomarkers

\begin{tabular}{|c|c|c|c|c|c|c|c|c|}
\hline & \multicolumn{8}{|l|}{ SLC7A8 } \\
\hline & \multicolumn{4}{|l|}{ mRNA } & \multicolumn{4}{|l|}{ protein } \\
\hline & $\begin{array}{l}\text { Low } \\
n(\%)\end{array}$ & $\begin{array}{l}\text { High } \\
n(\%)\end{array}$ & $\chi^{2}(P$ value $)$ & $\begin{array}{l}\text { Adjusted } \\
P \text { value }\end{array}$ & $\begin{array}{l}\text { Low } \\
n(\%)\end{array}$ & $\begin{array}{l}\text { High } \\
n(\%)\end{array}$ & $\chi^{2}(P$ value $)$ & $\begin{array}{l}\text { Adjusted } \\
P \text { value }\end{array}$ \\
\hline \multicolumn{9}{|l|}{ ER } \\
\hline Negative & $365(77.2)$ & $108(22.8)$ & $553.2\left(2.5 \times 10^{-122}\right)$ & $<0.0001$ & $296(89.4)$ & $35(10.6)$ & $0.09(0.76)$ & 1.52 \\
\hline Positive & $283(18.9)$ & $1215(81.1)$ & & & $1083(88.8)$ & $136(11.2)$ & & \\
\hline \multicolumn{9}{|l|}{ PR } \\
\hline Negative & $453(48.3)$ & 484 (51.7) & $193.6\left(5.0 \times 10^{-44}\right)$ & $<0.0001$ & $559(91.0)$ & $55(9.0)$ & $3.53(0.06)$ & 0.30 \\
\hline Positive & 195 (18.9) & 839 (81.1) & & & 807 (88.0) & $110(12.0)$ & & \\
\hline \multicolumn{9}{|l|}{ HER2 } \\
\hline Negative & $519(30.1)$ & $1206(69.9)$ & $48.7\left(2.9 \times 10^{-12}\right)$ & $<0.0001$ & $1174(88.3)$ & $155(11.7)$ & $8.82(0.003)$ & 0.01 \\
\hline Positive & $129(52.4)$ & 117 (47.6) & & & $198(95.2)$ & $10(4.8)$ & & \\
\hline \multicolumn{9}{|c|}{ Triple negative } \\
\hline No & $388(23.5)$ & $1263(76.5)$ & $405.07\left(4.3 \times 10^{-90}\right)$ & $<0.0001$ & $1169(89.4)$ & 139 (10.6) & $0.56(0.45)$ & 1.80 \\
\hline Yes & $260(81.3)$ & $60(18.8)$ & & & 207 (87.7) & $29(12.3)$ & & \\
\hline \multicolumn{9}{|c|}{ TP53 mutations } \\
\hline Wild-type & $204(28.5)$ & $512(71.5)$ & $38.36\left(4.6 \times 10^{-9}\right)$ & $<0.0001$ & Not available & & & \\
\hline Mutation & $59(59.6)$ & $40(40.4)$ & & & & & & \\
\hline \multicolumn{9}{|l|}{ p53 protein } \\
\hline Negative & Not available & & & & $860(89.0)$ & $106(11.0)$ & $0.24(0.62)$ & 1.86 \\
\hline Positive & & & & & 435 (89.9) & $49(10.1)$ & & \\
\hline
\end{tabular}

Bold indicates the significant values

disparity in their metabolic profiles and nutritional requirements. ER+/luminal tumours are the predominant BC subtype [30, 31] and characterised by having better prognosis and lower mortality rates as well as being targets for endocrine therapy [32]. In clinical practice, however, recognising patients who are likely to exhibit relapse or distant metastasis is challenging. Therefore, understanding the biology of $\mathrm{BC}$ is crucial in the pursuit of identifying targets for treatment and/or prognosis of BC patients particularly those with luminal tumours.

Altered metabolic pathways in human cancers are imperative to support cell proliferation and survival. Amino acid metabolism can vary substantially among BC subtypes, where TNBC display increased activity of amino acid consumption and metabolism compared with ER+ tumours $[33,34]$, suggesting that the latter subtype may allow for expression of lower levels of amino acid metabolic markers or express solute carriers that have lower affinity for their substrates. This study has revealed, for the first time, that SLC7A8 is a key amino acid transporter in the most predominant low proliferative ER+ tumours.

Unlike SLC7A5, SLC7A8 lacks studies that illustrate its prognostic role in human cancer. Data from Oncomine revealed a significant upregulation of SLC7A8 in several cancers, including breast, colorectal, head and neck, leukaemia, lymphoma, and melanoma [35]. However, this only has been validated at the mRNA level in a subset of breast tumours [15] and melanoma cell lines, which showed however more than five times increase in $S L C 7 A 5$ expression compared to $S L C 7 A 8$ [36]. Herein, we used large BC cohorts to reveal the significant associations between the high SLC7A8 expression, at mRNA and protein levels, and good prognostic clinicopathological parameters, including small tumour size, low tumour grade, and good NPI.

With respect to BC subtypes, the lowest levels of SLC7A8 mRNA were observed in the ER- and TNBC tumours, while SLC7A 8 was higher in the ER+ subtypes which was more prominent in the luminal A tumours. These results were compatible with other studies which showed that SLC7A8 mRNA was expressed in the ER+, MCF7, cell line but not in the ER-, MDA-MB-231 cells [37]. Furthermore, we have shown that SLC7A8 was associated with better patient outcome and longer DMFS in the ER+ low proliferative tumours only and not in the other subtypes. Thakkar et al. also found that upregulation of SLC7A8 alongside GATA3 and $M L P H$ significantly associated with longer relapse free survival in ER+ lymph node positive breast tumours [15]. These results may suggest that ER+ low proliferative tumours settle for the lower affinity transporter, SLC7A8, to satisfy their nutritional needs as they exhibit lower metabolic activity compared to the aggressive forms of BC. 


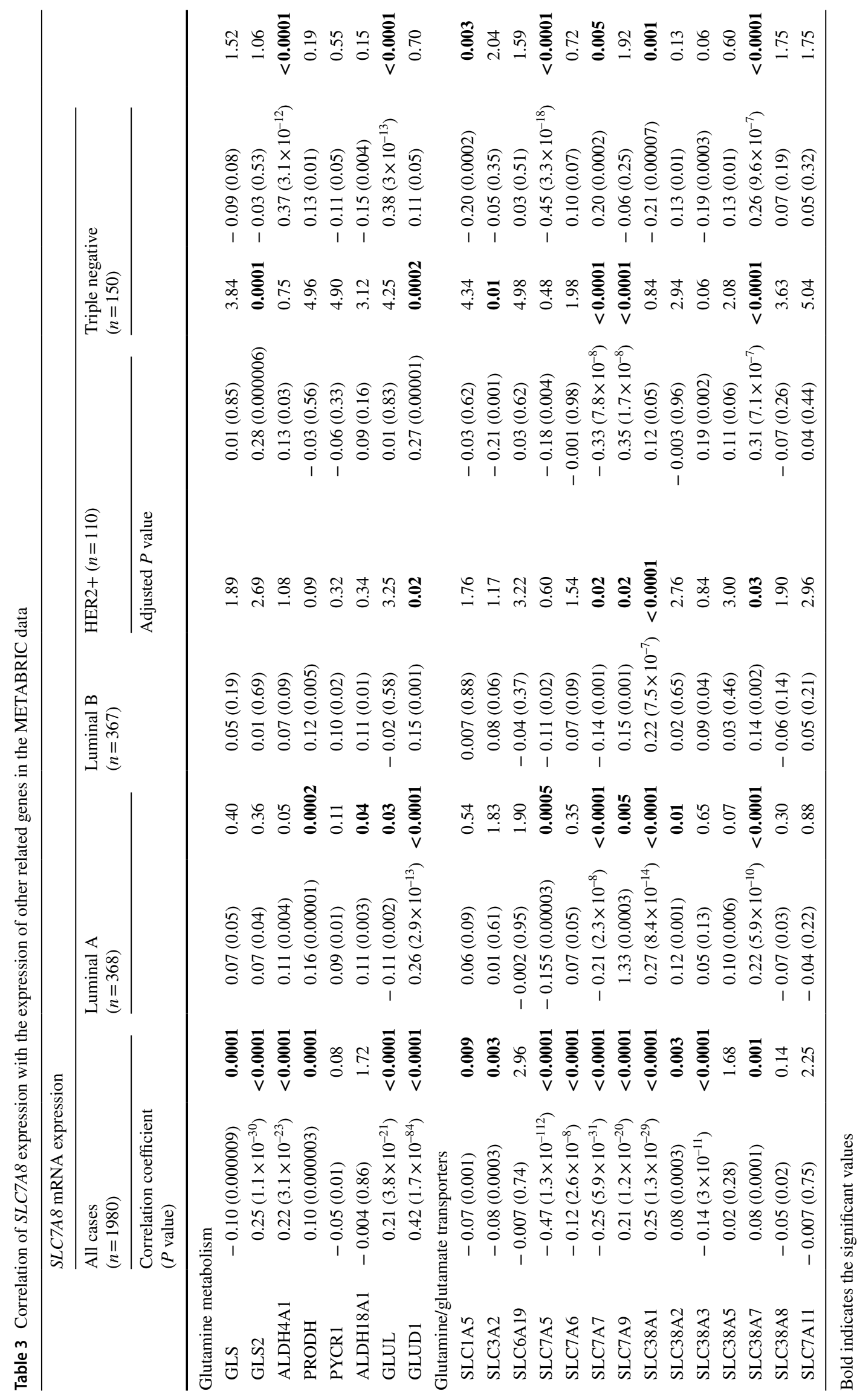


Table 4 Association between SLC7A8 protein expression and other biomarkers

\begin{tabular}{|c|c|c|c|}
\hline & \multicolumn{3}{|c|}{ S1C7A8 protein } \\
\hline & Low, $n(\%)$ & High, $n(\%)$ & $\chi^{2}(P$ value $)$ \\
\hline \multicolumn{4}{|l|}{ PRODH } \\
\hline Negative & 255 (89.8) & $29(10.2)$ & $10.93(0.001)$ \\
\hline Positive & $46(74.2)$ & $16(25.8)$ & \\
\hline \multicolumn{4}{|l|}{ GLS } \\
\hline Negative & $226(92.6)$ & $18(7.4)$ & $18.45(0.00001)$ \\
\hline Positive & 118 (77.6) & $34(22.4)$ & \\
\hline \multicolumn{4}{|l|}{ GLS2 } \\
\hline Negative & $171(89.5)$ & $20(10.5)$ & $7.41(0.006)$ \\
\hline Positive & 155 (79.5) & $40(20.5)$ & \\
\hline \multicolumn{4}{|l|}{ ALDH18A1 } \\
\hline Negative & $190(91.8)$ & $17(8.2)$ & $8.17(0.004)$ \\
\hline Positive & $157(82.2)$ & 34 (17.8) & \\
\hline \multicolumn{4}{|l|}{ ALDH4A1 } \\
\hline Negative & $185(92.0)$ & $16(8.0)$ & $11.19(0.001)$ \\
\hline Positive & $152(80.4)$ & 37 (19.6) & \\
\hline \multicolumn{4}{|l|}{ Positive } \\
\hline \multicolumn{4}{|l|}{ SLC7A5 } \\
\hline Negative & $1040(88.1)$ & 140 (11.9) & $4.66(0.03)$ \\
\hline Positive & 253 (92.7) & $20(7.3)$ & \\
\hline \multicolumn{4}{|l|}{ SLC38A2 } \\
\hline Negative & 992 (89.5) & $116(10.5)$ & $10.21(0.001)$ \\
\hline Positive & 89 (79.5) & $23(20.5)$ & \\
\hline \multicolumn{4}{|l|}{ SLC7A11 } \\
\hline Negative & 465 (92.1) & 40 (7.9) & $4.84(0.02)$ \\
\hline Positive & $580(88.1)$ & 78 (11.9) & \\
\hline
\end{tabular}

The relationship between hormone receptor positivity and $S L C 7 A 8$ indicate that hormone receptors have a possible role in stimulating $S L C 7 A 8$ expression. It has been shown that $17 \beta$ estradiol, in ER+ BC cells, regulates 1-leucine uptake through SLC7A5 and SLC7A8 while no effect was observed in the ER- BC cells [4]. It has been further shown that SLC7A8 has oestrogen-dependent expression, in ER+ $\mathrm{BC}$ cells, and the existence of inhibitors of oestrogen signalling pathway (ICI182780 and tamoxifen) eliminates the oestrogen-induced upregulation of SLC7A8 [15]. Another study also revealed that progesterone significantly upregulates $S L C 7 A 8$ mRNA and SLC7A8 protein expressions, in uterine leiomyoma tissues, and knockdown of SLC7A8 markedly increased leiomyoma cell proliferation [16].

P53 is a well-known tumour suppressor gene that responds to various stress signals through modulating other cellular processes, including cell cycle arrest and apoptosis. P53 also has a role in mediating other cellular mechanisms such as regulating metabolic pathways, including glutamine metabolism by inducing GLS2 expression [38]. Interestingly, this study showed a positive association between wild-type $P 53$ and SLC7A8. This suggests that SLC7A8 may contribute to P53-dependent tumour suppression, which resulted in the presence of favourable prognosis and patient outcome in tumours expressing high SLC7A8. In addition, SLC7A8 was upregulated alongside two tumour suppressor genes, CEACAM1 and BMP2, in human colon cancer cells after exposure to anti-tumour agent [39].

We have previously showed that SLC7A5 is highly expressed in the aggressive $\mathrm{BC}$ subtypes and it was predictive of poor prognosis and poor patient outcome [14] while analysing SLC7A8 in the same cohort has resulted in opposite findings. Furthermore, this study showed that SLC7A8 at both mRNA and protein levels were mutually exclusive with SLC7A5 expression. It is noteworthy that although SLC7A5 and SLC7A8 have similar substrate selectivity and function, the latter has narrower tissue expression pattern and exhibits lower affinity to its substrates [6]. There is also evidence which suggests that the role of SLC7A8 is limited to equilibration of amino acids distribution across the cell membrane while SLC7A5 mediates the actual net of amino acid flux [40], which is required for further mTORC1 activation and cellular proliferation.

Furthermore, it seems that both solute carriers have contrasting effect in tumourigenesis and they could be a subject of different regulatory mechanisms, as SLC7A5 expression is induced by c-MYC while hormone receptors appear to control SLC7A8 expression $[4,14,16]$.

This study further investigated the association of SLC7A8 expression with other solute carriers which involved in amino acid transport. While the majority of these transporters were negatively associated with SLC7A8, others were positively correlated, including SLC38A7 which showed consistent correlation in all BC subtypes. Positive associations with several glutamine metabolic enzymes were also detected, among these, GLS2 and glutamate dehydrogenase (GLUD1) which are associated with tumours of good prognosis and favourable patient outcome [21, 41]. Some variability in the expression of investigated markers across molecular subtypes was observed. For example, luminal A tumours were the main class which showed association between $S L C 7 A 8$ and markers required for glutamine transport and metabolism. This could be attributed to the increased SLC7A8 expression and function in this particular BC subtype.

It is noteworthy that different transcriptional pathways such as c-MYC oncogenic transcription, hormone receptors and nutrient starvation responses regulate the expression of amino acid transporters in human cancers [27, 35]. This also applies to SLC7A5 and SLC7A8, as both belong to the system $\mathrm{L}$ transport family but their expression is controlled by 

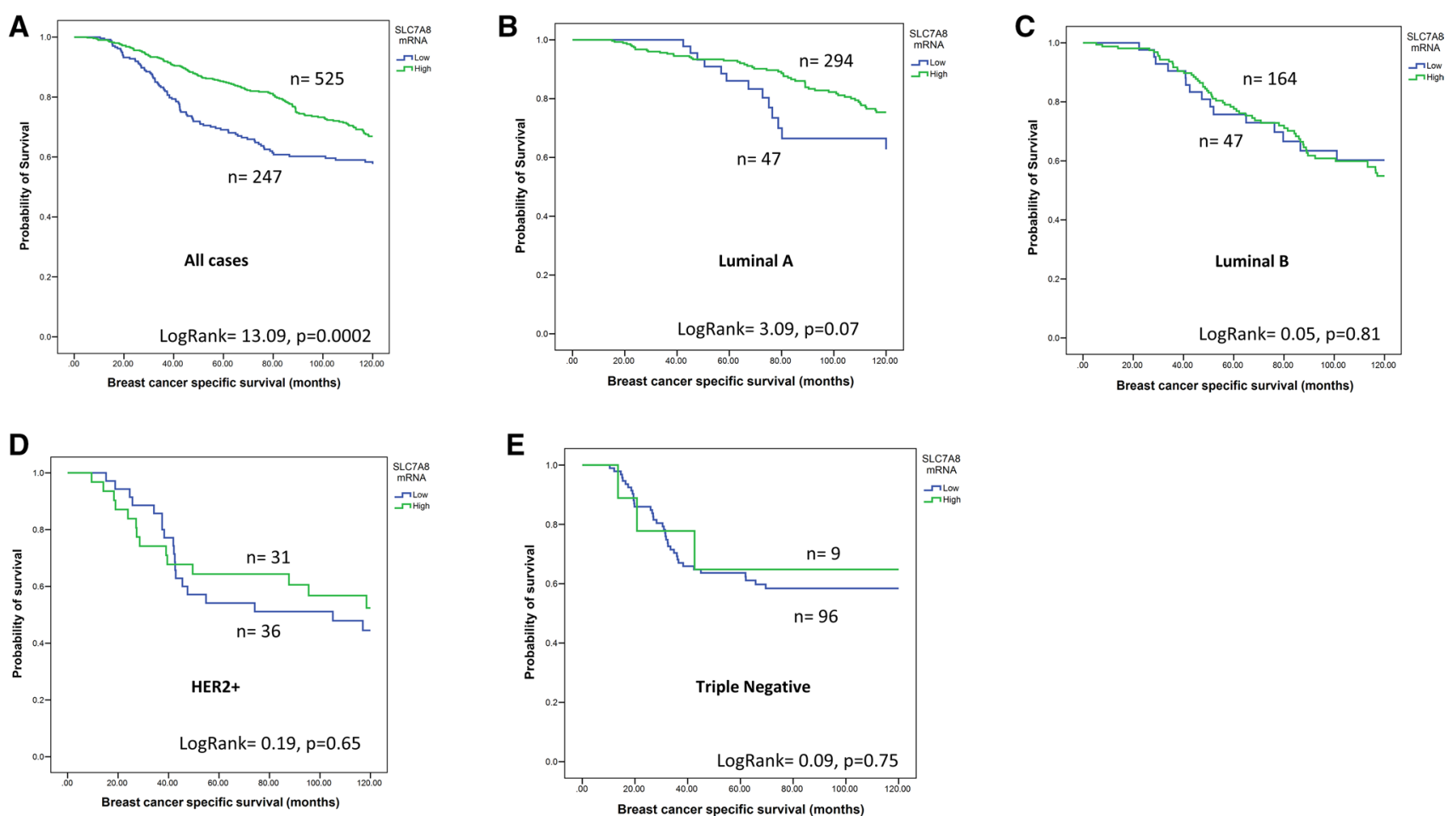

Fig. 3 SLC7A 8 mRNA and breast cancer patient outcome. a SLC7A8 vs BCSS in all cases, b SLC7A8 vs BCSS in luminal A tumours, c $S L C 7 A 8$ vs BCSS in Luminal B tumours, d SLC7A8 vs BCSS in HER2+ tumours, e SLC7A8 vs BCSS in Triple Negative tumours

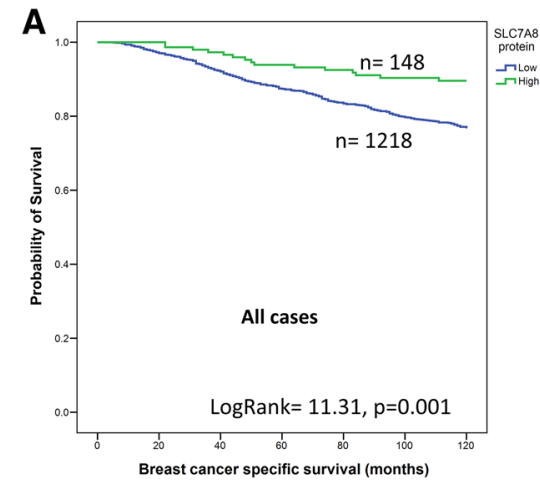

D

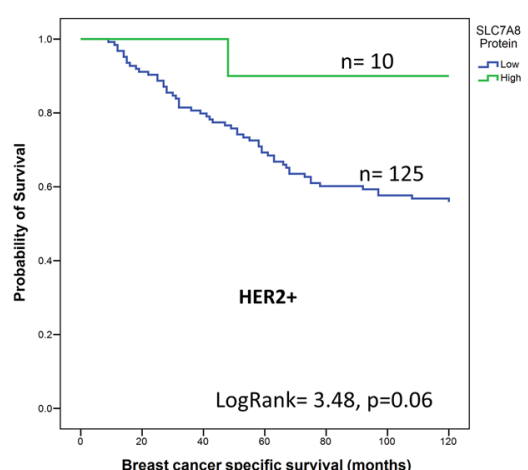

B

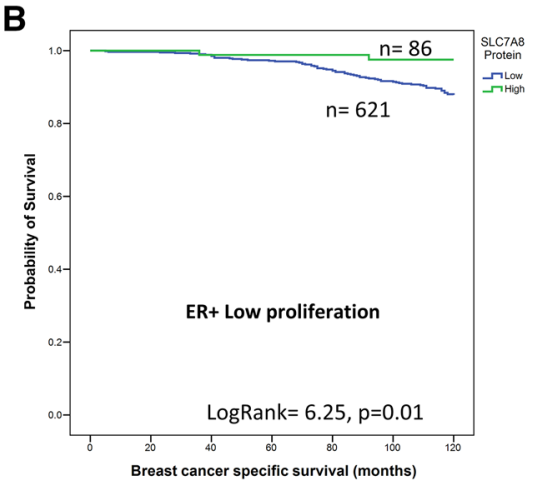

E

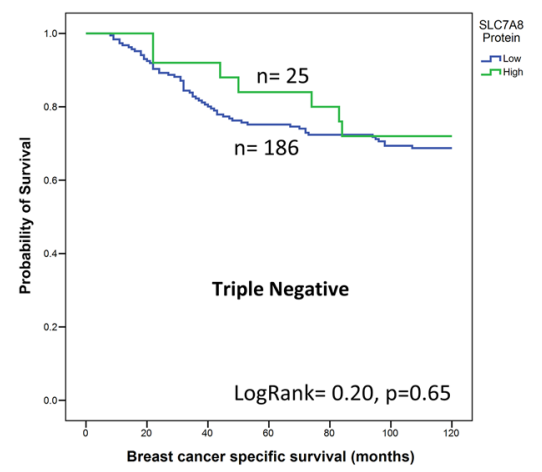

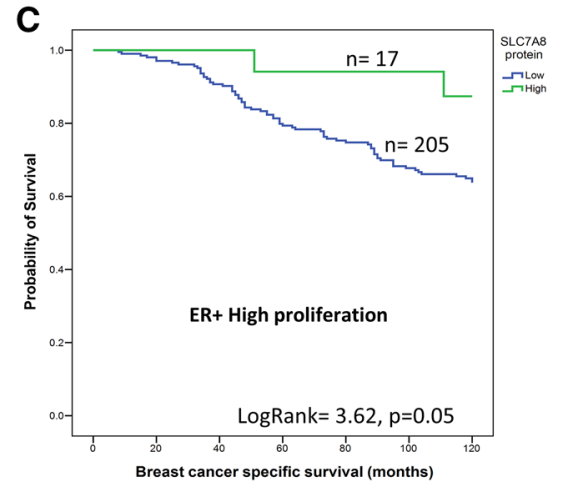

Fig. 4 SLC7A8 protein and breast cancer patient outcome. a SLC7A8 vs BCSS in all cases, b SLC7A8 vs BCSS of ER+- -low proliferation tumours, $\mathbf{c}$ SLC7A8 vs BCSS of ER+- -high Prolifera- tion tumours, d SLC7A8 vs BCSS of HER2+ tumours, e SLC7A8 vs BCSS of Triple Negative tumours 
Table 5 SLC7A8 mRNA/ protein expression and patient outcome in the all breast cancer cases

\begin{tabular}{|c|c|c|c|c|}
\hline \multirow[t]{2}{*}{ Parameter } & \multicolumn{2}{|l|}{ SLC7A8 mRNA } & \multicolumn{2}{|l|}{ SLC7A8 protein } \\
\hline & Hazard ratio $(95 \% \mathrm{CI})$ & $P$ value & Hazard ratio $(95 \% \mathrm{CI})$ & $P$ value \\
\hline SLC7A8 & $0.70(0.52-0.94)$ & 0.01 & $0.57(0.33-0.96)$ & 0.03 \\
\hline Lymph node stage & $2.00(1.56-2.55)$ & $2.4 \times 10^{-8}$ & $1.89(1.62-2.22)$ & $8.7 \times 10^{-16}$ \\
\hline Size & $1.48(0.99-2.20)$ & 0.05 & $1.39(1.08-1.78)$ & 0.009 \\
\hline Grade & $1.41(1.08-1.82)$ & 0.01 & $2.49(1.97-3.16)$ & $2.8 \times 10^{-14}$ \\
\hline
\end{tabular}

Bold indicates the significant values different pathways. Furthermore, both solute carriers mediate the uptake of large neutral amino acids, with the latter showing decreased transporting capacity. However, SLC7A8 can also accept smaller neutral amino acids, such as glycine, alanine, serine, cysteine, and glutamine [42], which are known substrates of the key system A amino acid transporter, SLC1A5 that is highly expressed in TNBC [6,43]. These statements indicate that SLC7A8 could be a key transporter in luminal A tumours through determining the actual net flux of not only the large but also the small neutral amino acids.

\section{Conclusion}

This study has revealed that the solute carrier SLC7A8 is an independent good prognostic marker in BC. Overexpression of SLC7A8 appears to have tumour suppressive characteristics especially in the low proliferative ER+ subtype, thus it could act as a potential prognostic factor. Functional assessment is necessary to reveal the specific role played by this amino acid transporter in the low proliferative ER+ tumours.

Acknowledgements We thank the Nottingham Health Science Biobank and Breast Cancer Now Tissue Bank for the provision of tissue samples.

Data availability The dataset analysed during the current study are available from the corresponding author on reasonable request.

\section{Compliance with ethical standards}

Conflict of interest The authors declare that they have no conflict of interest.

Research involving human participants and/or animals This study was approved by the Nottingham Research Ethics Committee 2 under the title 'Development of a molecular genetic classification of breast cancer' and the North West-Greater Manchester Central Research Ethics Committee under the title 'Nottingham Health Science Biobank (NHSB)' reference number 15/NW/0685. All procedures performed in studies involving human participants were in accordance with the ethical standards of the institutional and/or national research committee and with the 1964 Helsinki declaration and its later amendments or comparable ethical standards. Release of data were also pseudoanonymised as per the UK Human Tissue Act regulations. This article does not contain any studies with animals performed by any of the authors.

Informed consent All tissue samples from Nottingham used in this study were pseudoanonymised and collected prior to 1 st September 2006; therefore under the UK Human Tissue Act informed patient consent was not needed.

Open Access This article is licensed under a Creative Commons Attribution 4.0 International License, which permits use, sharing, adaptation, distribution and reproduction in any medium or format, as long as you give appropriate credit to the original author(s) and the source, provide a link to the Creative Commons licence, and indicate if changes were made. The images or other third party material in this article are included in the article's Creative Commons licence, unless indicated otherwise in a credit line to the material. If material is not included in the article's Creative Commons licence and your intended use is not permitted by statutory regulation or exceeds the permitted use, you will need to obtain permission directly from the copyright holder. To view a copy of this licence, visit http://creativecommons.org/licenses/by/4.0/.

\section{References}

1. Bond P (2016) Regulation of mTORC1 by growth factors, energy status, amino acids and mechanical stimuli at a glance. J Int Soc Sports Nutr 13:8. https://doi.org/10.1186/s12970-016-0118-y

2. Bar-Peled L, Sabatini DM (2014) Regulation of mTORC1 by amino acids. Trends Cell Biol 24(7):400-406. https://doi. org/10.1016/j.tcb.2014.03.003

3. Gao P, Tchernyshyov I, Chang TC, Lee YS, Kita K, Ochi T, Zeller KI, De Marzo AM, Van Eyk JE, Mendell JT, Dang CV (2009) c-Myc suppression of miR-23a/b enhances mitochondrial glutaminase expression and glutamine metabolism. Nature 458(7239):762-765. https://doi.org/10.1038/nature07823

4. Shennan DB, Thomson J, Gow IF, Travers MT, Barber MC (2004) L-leucine transport in human breast cancer cells (MCF-7 and MDA-MB-231): kinetics, regulation by estrogen and molecular identity of the transporter. Biochem Biophys Acta 1664(2):206216. https://doi.org/10.1016/j.bbamem.2004.05.008

5. Hellsten SV, Tripathi R, Ceder MM, Fredriksson R (2018) Nutritional stress induced by amino acid starvation results in changes for Slc38 transporters in immortalized hypothalamic neuronal cells and primary cortex cells. Front Mol Biosci 5:45. https://doi. org/10.3389/fmolb.2018.00045

6. Bhutia YD (1863) Ganapathy V (2016) Glutamine transporters in mammalian cells and their functions in physiology and cancer. Biochem Biophys Acta 10:2531-2539. https://doi.org/10.1016/j. bbamcr.2015.12.017 
7. Kanai Y, Segawa H, Miyamoto K, Uchino H, Takeda E, Endou H (1998) Expression cloning and characterization of a transporter for large neutral amino acids activated by the heavy chain of 4F2 antigen (CD98). J Biol Chem 273(37):23629-23632

8. Pineda M, Fernandez E, Torrents D, Estevez R, Lopez C, Camps M, Lloberas J, Zorzano A, Palacin M (1999) Identification of a membrane protein, LAT-2, that Co-expresses with 4F2 heavy chain, an L-type amino acid transport activity with broad specificity for small and large zwitterionic amino acids. J Biol Chem 274(28):19738-19744. https://doi.org/10.1074/jbc.274.28.19738

9. Rossier G, Meier C, Bauch C, Summa V, Sordat B, Verrey F, Kuhn LC (1999) LAT2, a new basolateral 4F2hc/CD98-associated amino acid transporter of kidney and intestine. J Biol Chem 274(49):34948-34954. https://doi.org/10.1074/jbc.274.49.34948

10. Kobayashi H, Ishii Y, Takayama T (2005) Expression of L-type amino acid transporter 1 (LAT1) in esophageal carcinoma. J Surg Oncol 90(4):233-238. https://doi.org/10.1002/jso.20257

11. Yoon JH, Kim IJ, Kim H, Kim HJ, Jeong MJ, Ahn SG, Kim SA, Lee CH, Choi BK, Kim JK, Jung KY, Lee S, Kanai Y, Endou H, Kim DK (2005) Amino acid transport system L is differently expressed in human normal oral keratinocytes and human oral cancer cells. Cancer Lett 222(2):237-245. https:// doi.org/10.1016/j.canlet.2004.09.040

12. Nakanishi K, Matsuo H, Kanai Y, Endou H, Hiroi S, Tominaga S, Mukai M, Ikeda E, Ozeki Y, Aida S, Kawai T (2006) LAT1 expression in normal lung and in atypical adenomatous hyperplasia and adenocarcinoma of the lung. Virchows Arch 448(2):142-150. https://doi.org/10.1007/s00428-005-0063-7

13. Furuya M, Horiguchi J, Nakajima H, Kanai Y, Oyama T (2012) Correlation of L-type amino acid transporter 1 and CD98 expression with triple negative breast cancer prognosis. Cancer Sci 103(2):382-389. https://doi.org/10.111 1/j.1349-7006.2011.02151.x

14. El Ansari R, Craze ML, Miligy I, Diez-Rodriguez M, Nolan CC, Ellis IO, Rakha EA, Green AR (2018) The amino acid transporter SLC7A5 confers a poor prognosis in the highly proliferative breast cancer subtypes and is a key therapeutic target in luminal B tumours. Breast Cancer Res 20(1):21. https://doi. org/10.1186/s13058-018-0946-6

15. Thakkar A, Raj H, Ravishankar MB, Balakrishnan A, Padigaru M (2015) High expression of three-gene signature improves prediction of relapse-free survival in estrogen receptor-positive and node-positive breast tumors. Biomark insights 10:103-112. https://doi.org/10.4137/bmi.S30559

16. Luo X, Yin P, Reierstad S, Ishikawa H, Lin Z, Pavone ME, Zhao H, Marsh EE, Bulun SE (2009) Progesterone and mifepristone regulate L-type amino acid transporter 2 and $4 \mathrm{~F} 2$ heavy chain expression in uterine leiomyoma cells. J Clin Endocrinol Metab 94(11):4533-4539. https://doi.org/10.1210/jc.2009-1286

17. Curtis C, Shah SP, Chin SF, Turashvili G, Rueda OM, Dunning MJ, Speed D, Lynch AG, Samarajiwa S, Yuan Y, Graf S, Ha G, Haffari G, Bashashati A, Russell R, McKinney S, Langerod A, Green A, Provenzano E, Wishart G, Pinder S, Watson P, Markowetz F, Murphy L, Ellis I, Purushotham A, BorresenDale AL, Brenton JD, Tavare S, Caldas C, Aparicio S (2012) The genomic and transcriptomic architecture of 2,000 breast tumours reveals novel subgroups. Nature 486(7403):346-352. https://doi.org/10.1038/nature10983

18. Craze ML, Cheung H, Jewa N, Coimbra ND, Soria D, ElAnsari R, Aleskandarany MA, Cheng KW, Diez-Rodriguez M, Nolan CC (2017) MYC regulation of Glutamine-Proline regulatory axis is key in Luminal $\mathrm{B}$ breast cancer. Br J Cancer 118(2):258-265

19. Abd El-Rehim DM, Ball G, Pinder SE, Rakha E, Paish C, Robertson JF, Macmillan D, Blamey RW, Ellis IO (2005) High-throughput protein expression analysis using tissue microarray technology of a large well-characterised series identifies biologically distinct classes of breast cancer confirming recent cDNA expression analyses. Int J Cancer 116(3):340-350. https://doi.org/10.1002/ ijc. 21004

20. McCarty KS Jr, McCarty KS Sr (1984) Histochemical approaches to steroid receptor analyses. Semin Diagn Pathol 1(4):297-308

21. Craze ML, El-Ansari R, Aleskandarany MA, Cheng KW, Alfarsi L, Masisi B, Diez-Rodriguez M, Nolan CC, Ellis IO, Rakha EA, Green AR (2019) Glutamate dehydrogenase (GLUD1) expression in breast cancer. Breast Cancer Res Treat 174(1):79-91. https:// doi.org/10.1007/s 10549-018-5060-z

22. Green AR, Aleskandarany MA, Agarwal D, Elsheikh S, Nolan CC, Diez-Rodriguez M, Macmillan RD, Ball GR, Caldas C, Madhusudan S, Ellis IO, Rakha EA (2016) MYC functions are specific in biological subtypes of breast cancer and confers resistance to endocrine therapy in luminal tumours. Br J Cancer 114(8):917928. https://doi.org/10.1038/bjc.2016.46

23. Elston CW, Ellis IO (2002) Pathological prognostic factors in breast cancer. I. The value of histological grade in breast cancer: experience from a large study with long-term follow-up. C. W. Elston \& I. O. Ellis. Histopathology 1991; 19; 403-410. Histopathology 41 (3a):151-152, discussion 152-153

24. Senkus E, Kyriakides S, Ohno S, Penault-Llorca F, Poortmans P, Rutgers E, Zackrisson S, Cardoso F (2015) Primary breast cancer: ESMO Clinical Practice Guidelines for diagnosis, treatment and follow-up. Ann Oncol 26(Suppl 5):v8-30. https://doi.org/10.1093/ annonc/mdv298

25. McShane LM, Altman DG, Sauerbrei W, Taube SE, Gion M, Clark GM (2005) REporting recommendations for tumour MARKer prognostic studies (REMARK). Br J Cancer 93(4):387391. https://doi.org/10.1038/sj.bjc.6602678

26. Pochini L, Scalise M, Galluccio M, Indiveri C (2014) Membrane transporters for the special amino acid glutamine: structure/function relationships and relevance to human health. Front Chem 2:61. https://doi.org/10.3389/fchem.2014.00061

27. El Ansari R, McIntyre A, Craze ML, Ellis IO, Rakha EA, Green AR (2018) Altered glutamine metabolism in breast cancer; subtype dependencies and alternative adaptations. Histopathology 72(2):183-190. https://doi.org/10.1111/his.13334

28. Cha YJ, Kim ES, Koo JS (2018) Amino acid transporters and glutamine metabolism in breast cancer. Int J Mol Sci 19(3):907. https://doi.org/10.3390/ijms19030907

29. Perou CM, Sorlie T, Eisen MB, van de Rijn M, Jeffrey SS, Rees CA, Pollack JR, Ross DT, Johnsen H, Akslen LA, Fluge O, Pergamenschikov A, Williams C, Zhu SX, Lonning PE, BorresenDale AL, Brown PO, Botstein D (2000) Molecular portraits of human breast tumours. Nature 406(6797):747-752. https://doi. org/10.1038/35021093

30. Rakha EA, El-Sayed ME, Green AR, Paish EC, Powe DG, Gee J, Nicholson RI, Lee AH, Robertson JF, Ellis IO (2007) Biologic and clinical characteristics of breast cancer with single hormone receptor positive phenotype. J Clin Oncol 25(30):4772-4778. https://doi.org/10.1200/jco.2007.12.2747

31. Dawson SJ, Rueda OM, Aparicio S, Caldas C (2013) A new genome-driven integrated classification of breast cancer and its implications. EMBO J 32(5):617-628. https://doi.org/10.1038/ emboj.2013.19

32. Ring BZ, Seitz RS, Beck R, Shasteen WJ, Tarr SM, Cheang MC, Yoder BJ, Budd GT, Nielsen TO, Hicks DG, Estopinal NC, Ross DT (2006) Novel prognostic immunohistochemical biomarker panel for estrogen receptor-positive breast cancer. J Clin Oncol 24(19):3039-3047. https://doi.org/10.1200/jco.2006.05.6564

33. Kanaan YM, Sampey BP, Beyene D, Esnakula AK, Naab TJ, Ricks-Santi LJ, Dasi S, Day A, Blackman KW, Frederick W, Copeland RL Sr, Gabrielson E, Dewitty RL Jr (2014) Metabolic profile of triple-negative breast cancer in African-American 
women reveals potential biomarkers of aggressive disease. Cancer Genomics Proteom 11(6):279-294

34. Cao MD, Lamichhane S, Lundgren S, Bofin A, Fjosne H, Giskeodegard GF, Bathen TF (2014) Metabolic characterization of triple negative breast cancer. BMC Cancer 14:941. https://doi. org/10.1186/1471-2407-14-941

35. Wang Q, Holst J (2015) L-type amino acid transport and cancer: targeting the mTORC1 pathway to inhibit neoplasia. Am J Cancer Res 5(4):1281-1294

36. Wang Q, Beaumont KA, Otte NJ, Font J, Bailey CG, van Geldermalsen M, Sharp DM, Tiffen JC, Ryan RM, Jormakka M, Haass NK, Rasko JE, Holst J (2014) Targeting glutamine transport to suppress melanoma cell growth. Int J Cancer 135(5):1060-1071. https://doi.org/10.1002/ijc.28749

37. Shennan DB, Thomson J, Barber MC, Travers MT (2003) Functional and molecular characteristics of system $\mathrm{L}$ in human breast cancer cells. Biochem Biophys Acta 1611(1-2):81-90. https://doi. org/10.1016/s0005-2736(03)00028-2

38. Suzuki S, Tanaka T, Poyurovsky MV, Nagano H, Mayama T, Ohkubo S, Lokshin M, Hosokawa H, Nakayama T, Suzuki Y, Sugano S, Sato E, Nagao T, Yokote K, Tatsuno I, Prives C (2010) Phosphate-activated glutaminase (GLS2), a p53-inducible regulator of glutamine metabolism and reactive oxygen species. Proc Natl Acad Sci USA 107(16):7461-7466. https://doi.org/10.1073/ pnas. 1002459107

39. Bermudez-Soto MJ, Larrosa M, Garcia-Cantalejo JM, Espin JC, Tomas-Barberan FA, Garcia-Conesa MT (2007) Up-regulation of tumor suppressor carcinoembryonic antigen-related cell adhesion molecule 1 in human colon cancer Caco- 2 cells following repetitive exposure to dietary levels of a polyphenol-rich chokeberry juice. J Nutr Biochem 18(4):259-271. https://doi.org/10.1016/j. jnutbio.2006.05.003

40. Meier C, Ristic Z, Klauser S, Verrey F (2002) Activation of system $\mathrm{L}$ heterodimeric amino acid exchangers by intracellular substrates. EMBO J 21(4):580-589. https://doi.org/10.1093/emboj /21.4.580

41. Liu J, Zhang C, Lin M, Zhu W, Liang Y, Hong X, Zhao Y, Young $\mathrm{KH}, \mathrm{Hu} \mathrm{W}$, Feng Z (2014) Glutaminase 2 negatively regulates the PI3K/AKT signaling and shows tumor suppression activity in human hepatocellular carcinoma. Oncotarget 5(9):2635-2647. https://doi.org/10.18632/oncotarget.1862

42. del Amo EM, Urtti A, Yliperttula M (2008) Pharmacokinetic role of L-type amino acid transporters LAT1 and LAT2. Eur J Pharm Sci 35(3):161-174. https://doi.org/10.1016/j.ejps.2008.06.015

43. van Geldermalsen $M$, Wang $Q$, Nagarajah $R$, Marshall $A D$, Thoeng A, Gao D, Ritchie W, Feng Y, Bailey CG, Deng N, Harvey K, Beith JM, Selinger CI, O'Toole SA, Rasko JE, Holst J (2016) ASCT2/SLC1A5 controls glutamine uptake and tumour growth in triple-negative basal-like breast cancer. Oncogene 35(24):32013208. https://doi.org/10.1038/onc.2015.381

Publisher's Note Springer Nature remains neutral with regard to jurisdictional claims in published maps and institutional affiliations. 